Chapter 10

\title{
Pushover Analysis of Long Span Bridge Bents
}

\author{
Vitaly Yurtaev and Reza Shafiei \\ Additional information is available at the end of the chapter \\ http://dx.doi.org/10.5772/52728
}

\section{Introduction}

It has been observed that most of the bridges damaged in earthquakes were constructed before 1971 and had little or no design consideration to seismic resistance. Since the 1971 San Fernando earthquake in California, the standards for earthquake design have been strengthened considerably, and bridge structural behavior has been more accurately evaluated. Since then, structural ductility, a crucial element for the survival of bridges under severe earthquakes has become a key consideration in structural analysis and design.

However, bridges that were constructed prior to 1971 are still in use and play important roles in our transportation systems, which may be susceptible to failure due to their structural deficiencies. To ensure safety and performance of these bridges, a seismic retrofit and strengthening program has been one of the major efforts of the Washington Department of Transportation and the Federal Highway Administration, aiming at improving seismic performance of older bridges. Retrofitting methods such as restrainers and column jacketing have proven to be effective in recent earthquakes. Techniques to retrofit other bridge members have also been developed such as soil anchors, footing retrofit involving increased plan dimension and reinforced overlay, construction of link beams, and system isolation and damping device.

The goal of seismic retrofit is to minimize the likelihood of structural failure while meeting certain performance requirements. This allows engineers to design repair strategies based on performance needs. As a consequence, some level of damage may be acceptable during a design-level earthquake. The California Department of Transportation (Caltrans) has required that bridge retrofits provide survival limit-state protection at seismic intensities appropriate for new bridges. This makes possible the proposition of efficient and effective strengthening measures with optimized retrofitting schemes, and the adoption of the plan that is the most economical for the acceptable damage level. One of the ways of implementation the retrofit program for the structures is providing a nonlinear static analysis. 
Nonlinear static analysis under monotonically increasing lateral loading is becoming an increasingly popular tool for seismic performance evaluation of existing and new structures. Pushover analysis can be viewed as a method for predicting seismic force and deformation demands, which accounts in an approximate manner for the redistribution of internal forces occurring within the inelastic range of structural behavior. It is expected to provide information on many response characteristics that cannot be obtained from an elastic static or dynamic analysis. Pushover analysis is based on the assumption that the response of the structure can be related to the response of an equivalent SDOF system. This implies that the response is controlled by a single mode, and that the shape of this mode remains constant through the time history response. These assumptions are likely to be reasonable if the structure response is not severely affected by higher mode effects, or the structure has only a single plastic mechanism that can be detected by an invariant load pattern. The use of at least two load patterns that are expected to bound inertia force distribution is recommended. For structures that vibrate primarily in the fundamental mode, pushover analysis will very likely provide good estimates of global as well as local inelastic deformation demands. It will also expose design weaknesses that may remain hidden in an elastic analysis. Such weaknesses include storey mechanisms, excessive deformation demands, strength irregularity, and overloads on potentially brittle elements, such as columns and connections. On the negative side, the most critical is the concern that the pushover analysis may detect only the first local mechanism that will form in an earthquake and may not expose other weaknesses that will be generated when the structure's dynamic characteristics change after the formation of the first local mechanism.

\section{Objectives of the analysis}

The purpose of this research is to evaluate the displacement capacity of bents from a long span bridge. A three-dimensional nonlinear finite-element model of the bridge bents were developed to determine the inelastic response by performing nonlinear pushover analysis. Modal pushover analyses were carried out in the transverse direction. Detailed data of performance was collected and interpreted to use as a baseline in a parametric study. Separate parametric study was carried out on a single column within this bridge in order to locate appropriate plastic hinge locations. These results were then transferred to individual bents, where multiple columns were modeled based on the results from the single column parametric study.

\section{Description of the bridge}

The bridge is located at the Primary State Highway No.1, Seattle Freeway Ravenna Boulevard Overcrossing North Bound. Figure 1 shows an aerial view of the bridge. The North Bound Bridge is the first bridge from below shown in the picture. The bridge length is $1310 \mathrm{ft}$ back to back of pavement seats and consists of twenty spans. Plan and elevation views are shown in Figure 2 and Figure 3. 


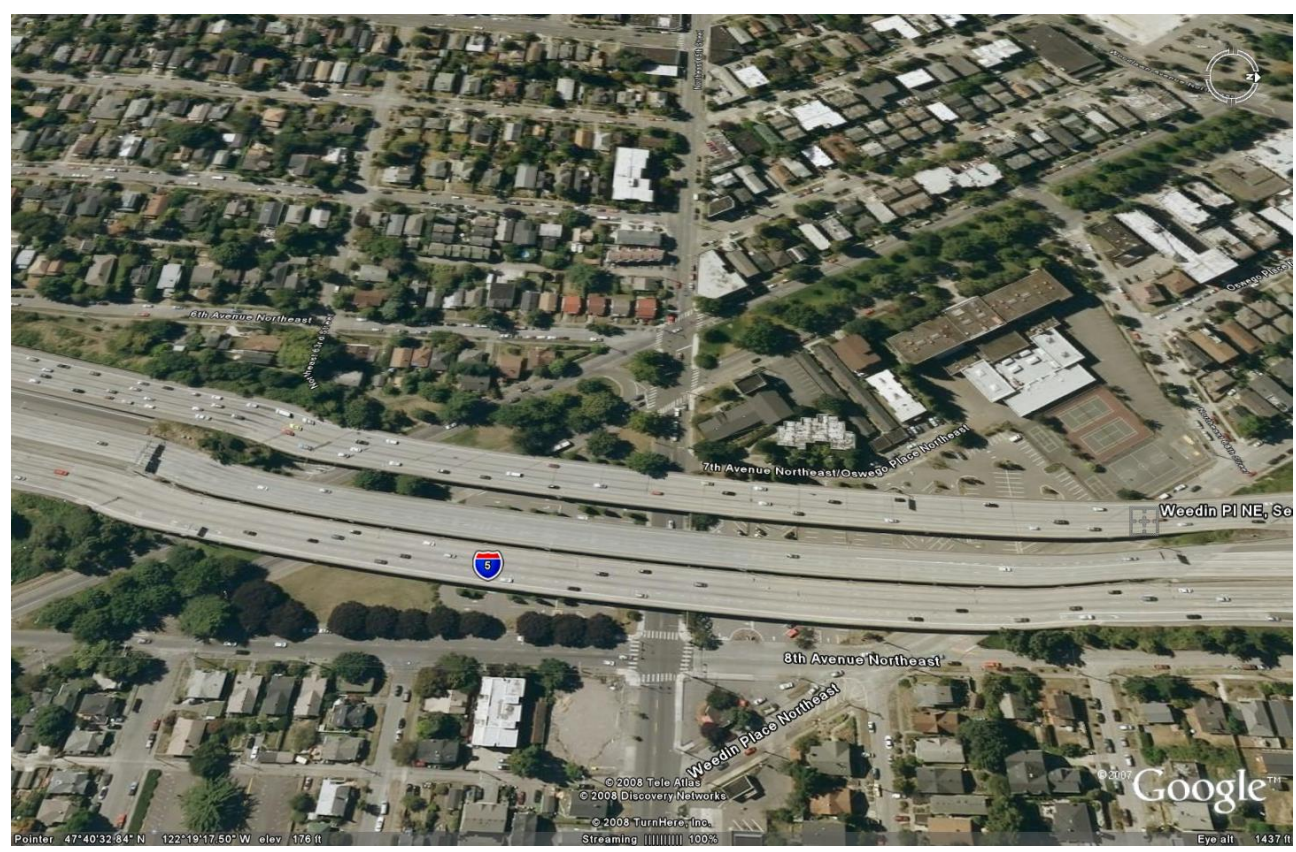

Figure 1. Aerial view of the North Bound bridge

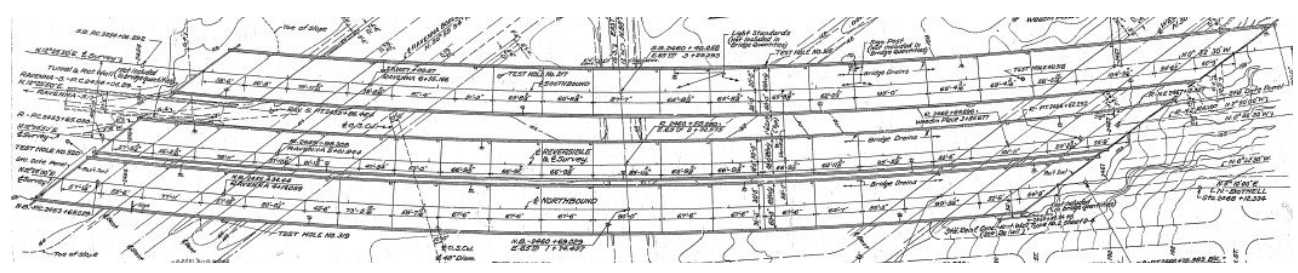

Figure 2. Plan view of the North Bound Bridge

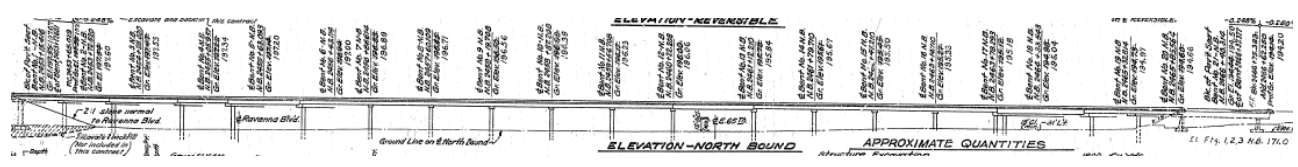

Figure 3. Elevation view of the North Bound Bridge 
The superstructure is composed of pre-tensioned concrete beams. Each span includes twelve girders, and the general girder cross-section varies for each span. This complicates the calculation of the total mass of the superstructure. In order to simplify the procedure, individual span cross-sections were drawn in AutoCAD. The sections can be found is Figure 4 relating them to the spans they are assembled for. A table with calculated weight and length for each span can be found in the Appendix. Overlaid on top of the girders is a 5 in thick, approximately $60 \mathrm{ft}$ wide reinforced concrete deck slab.
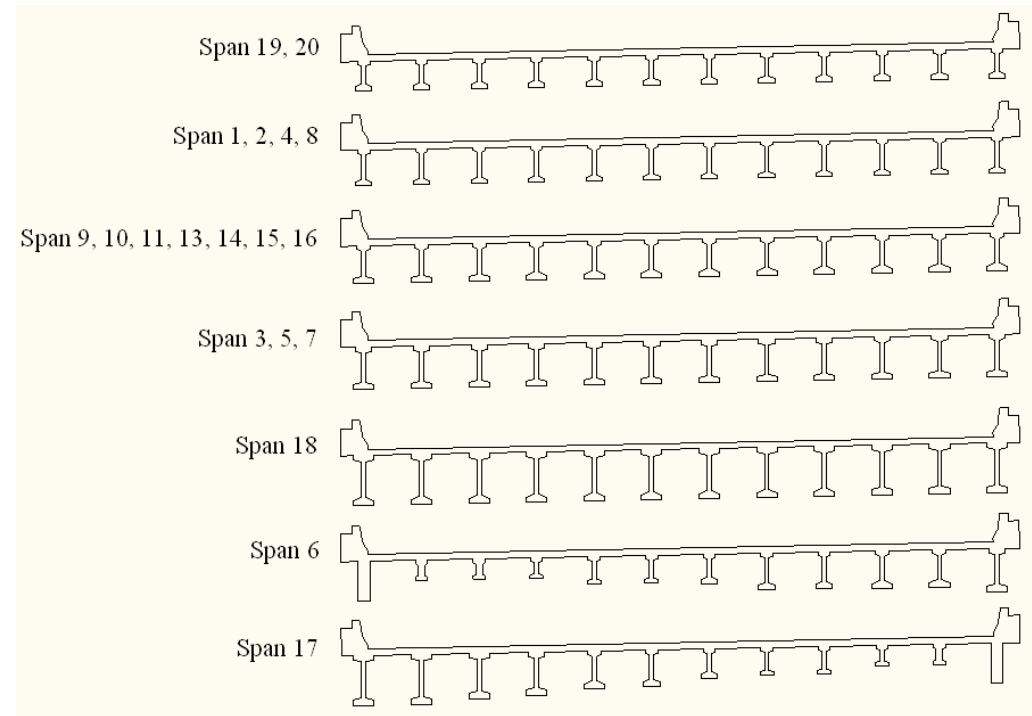

Figure 4. Superstructure Sections

There are a total of 19 bents in the bridge. Five are 6-column bents (\#1-6), three are 7-column bents (\#18-20) and ten are 4-column bents (\#7-17). The cross-beam plans for the three types of bents are shown in Figure 5. Each bent has a unique elevation above the ground. Also, because of the curved shape of the bridge, each bent has a slight rotation in the vertical direction. Consequently, there is column height variation within each bent. The various column height values can be found in the Appendix.

At each bent, a $3 \times 4.6 \mathrm{ft}$ crossbeam transversely connects the columns. Figure 6 below shows the geometry and steel reinforcement. The length of the beams varies for each bent, which can be found in the Appendix. The steel reinforcement consists of nine No. 10 bars located at the top and at the bottom of each crossbeam. Two No. 5 bars are located at the side edges and run longitudinally along the crossbeam. For shear reinforcement, No. 5 stirrups are spaced evenly along each member. 

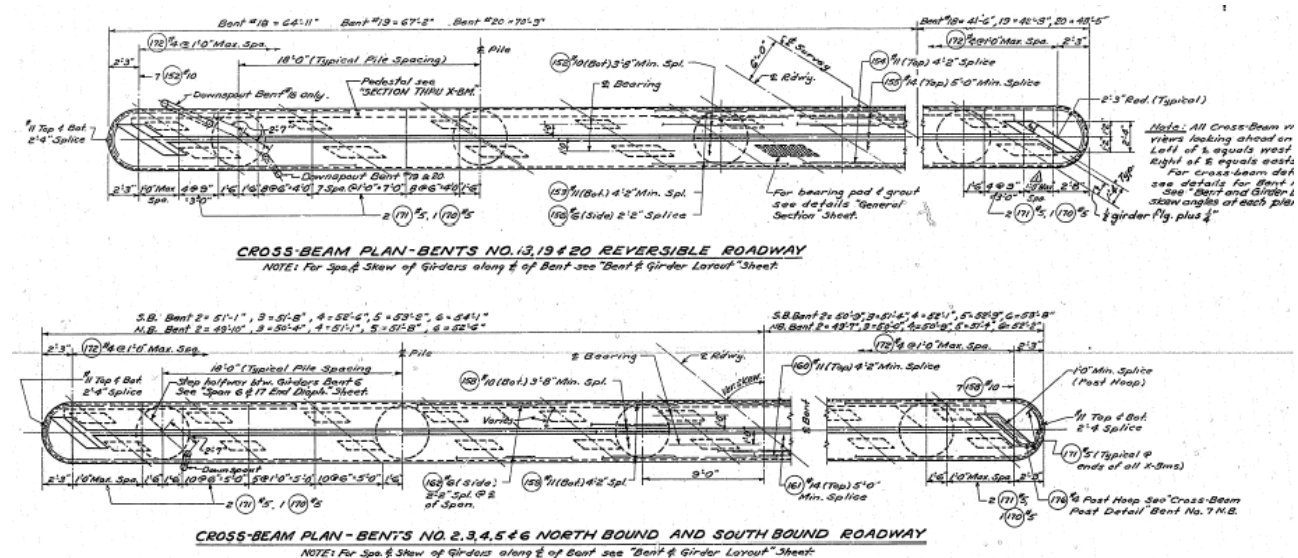

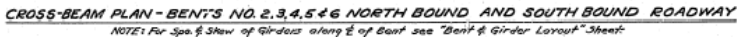

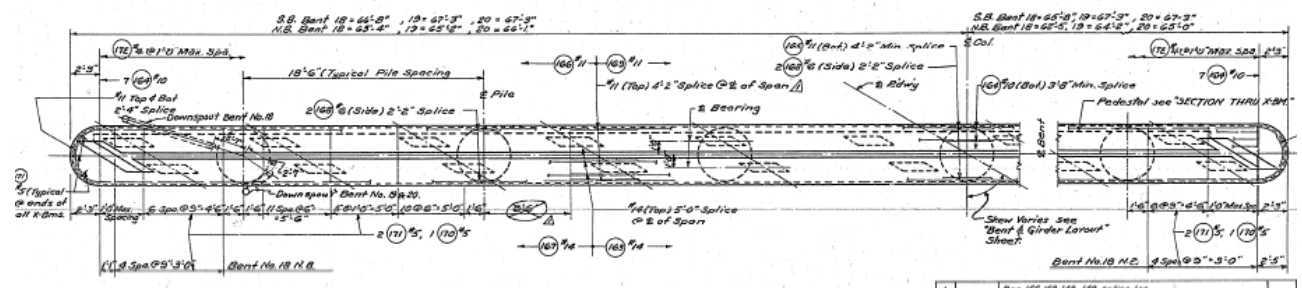

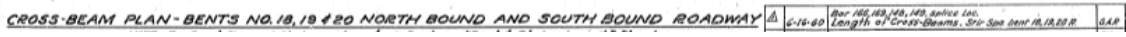

Figure 5. Cross-Beam Plan for Bents

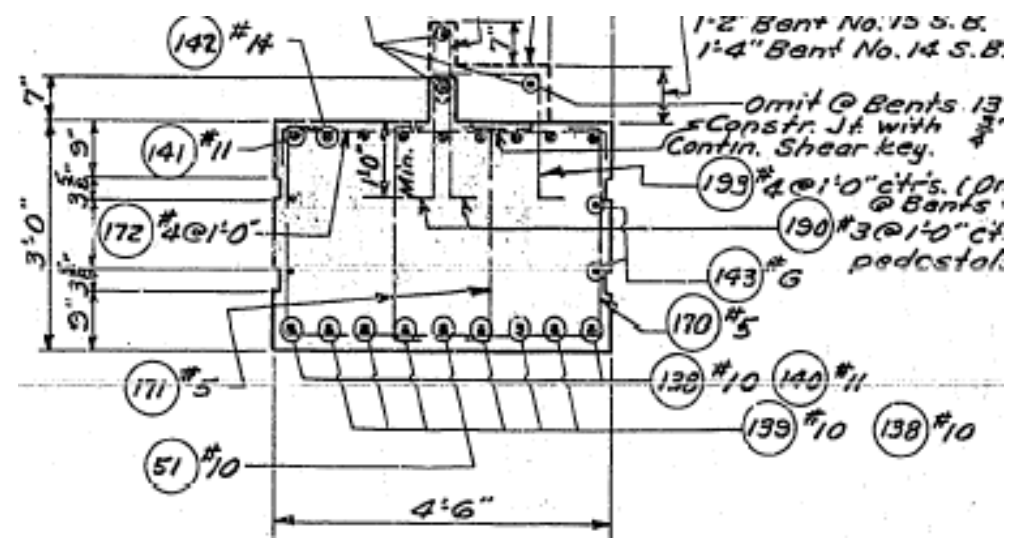

Figure 6. Section Thru Cross-Beam

The columns are spaced at $18 \mathrm{ft}$ centerline to centerline. Each column is hollow with an outer diameter of 48 in and a wall thickness of 5 in. Twelve evenly spaced No. 5 bars provide the longitudinal reinforcement within each column. The columns also include twelve No. 3 steel 
cables each post-tensioned initially to $61 \mathrm{kips}$. Transverse reinforcement is provided by No. 2 spiral hooping spaced at 6 in on center. Figure 7 shows the plan column section. The columns are extended approximately $27 \mathrm{ft}$ into the ground to act as piles.

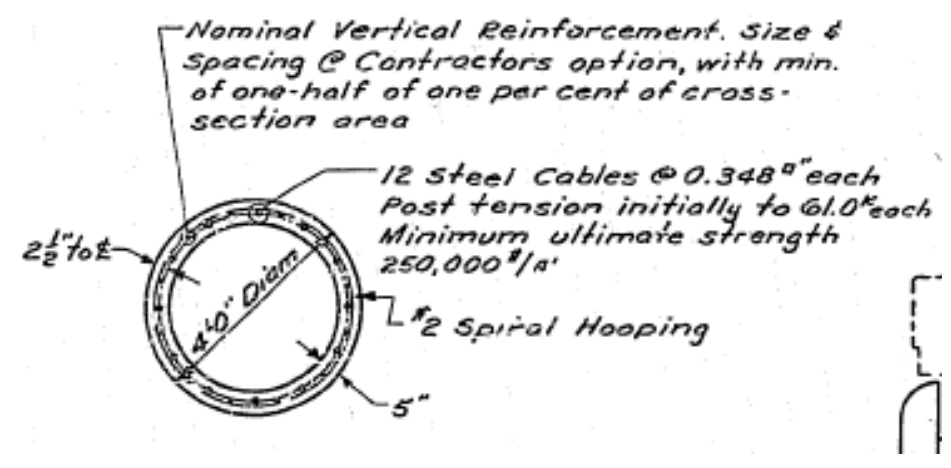

Figure 7. Plan Column Section

The columns and crossbeam were cast monolithically adding considerable rigidity to each bent. Figure 8 shows the elevation view of a typical bent. Further, the top $4 \mathrm{ft}$ of each column is filled with class A concrete. This fill is further reinforced with sixteen No. 8 bars longitudinally, and No. 3 hoops spaced at 12 in transversely. In this section of the column, the hollow column is transversely reinforced with No. 2 spiral hooping spaced at 3 in over center. Figure 9 shows a typical pile.

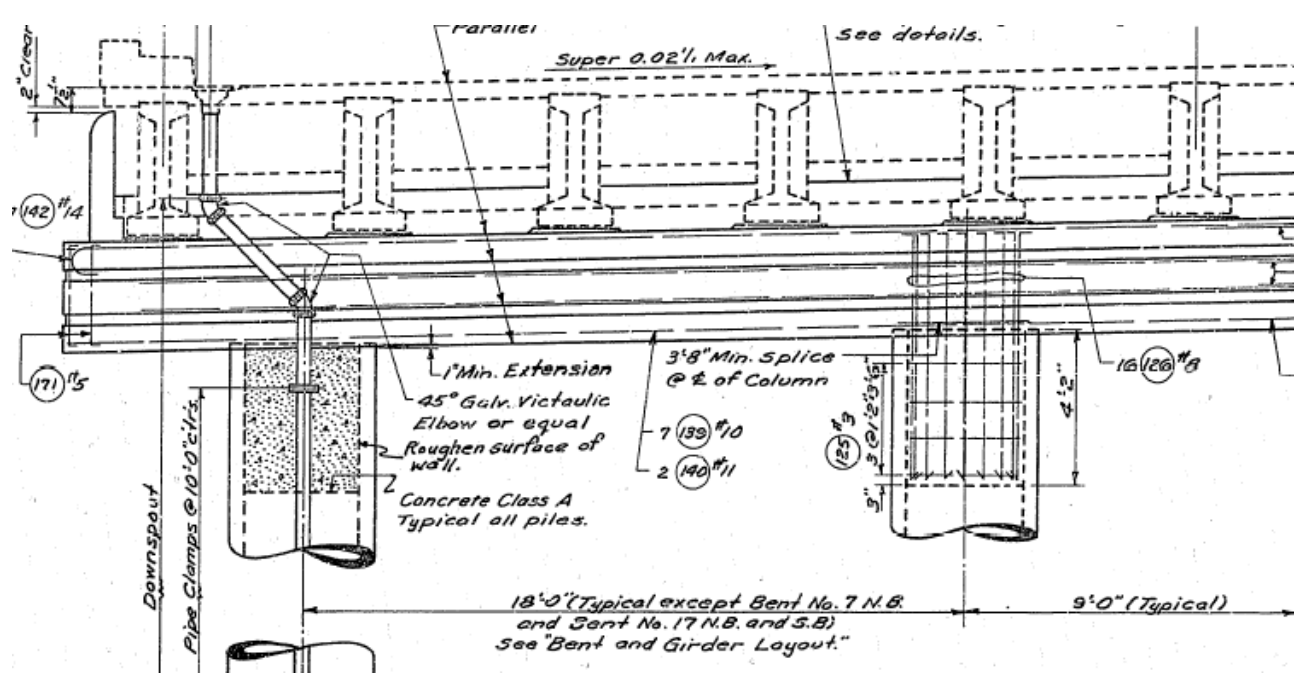

Figure 8. Elevation View of Bents 


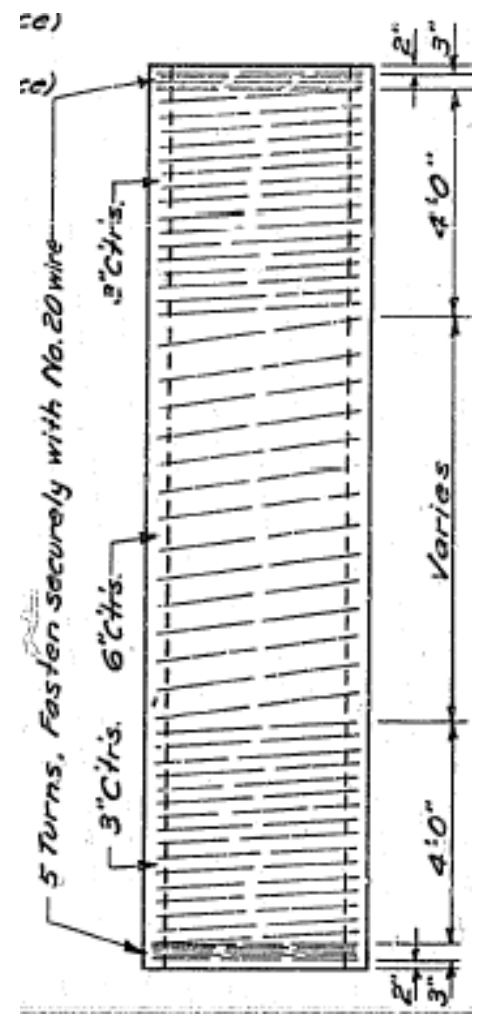

Figure 9. Typical Pile

\section{Modeling of the bents}

A spine model of each bent is created in the finite element program SAP2000. Line elements can behave three-dimensionally in the form of beam, beam-column elements and springs. The superstructure is represented as a distributed dead load which represents the dead weight of the superstructure based on tributary length of related spans for each bent. A table in the Appendix provides the distributed load values used in the analysis for each bent. The soilstructure interaction is represented by springs. In order to capture nonlinear behavior of the columns, plastic hinges were defined at maximum moment points. The general model is represented in 3D in Figure 10. 


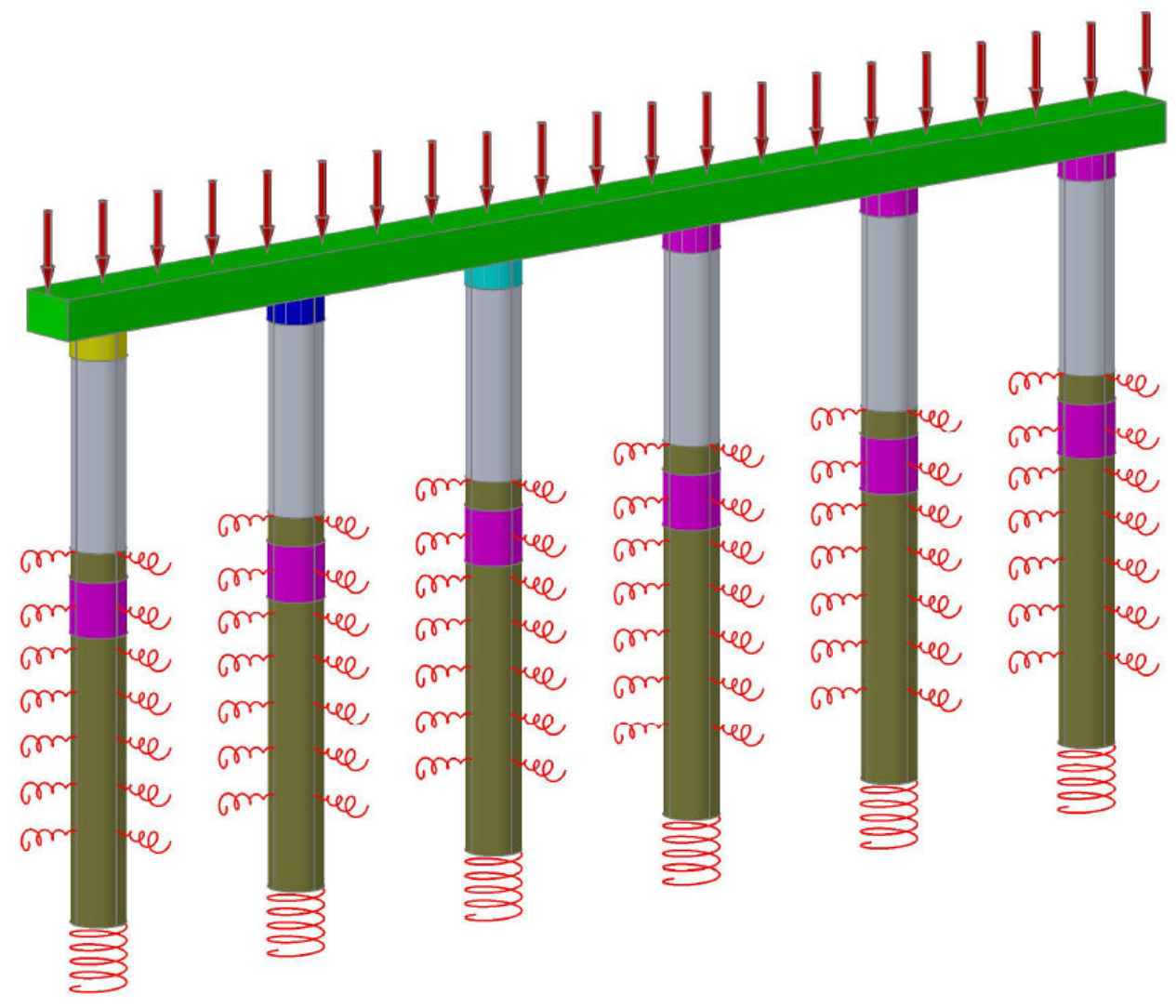

Figure 10. Model of Six-Column Bents
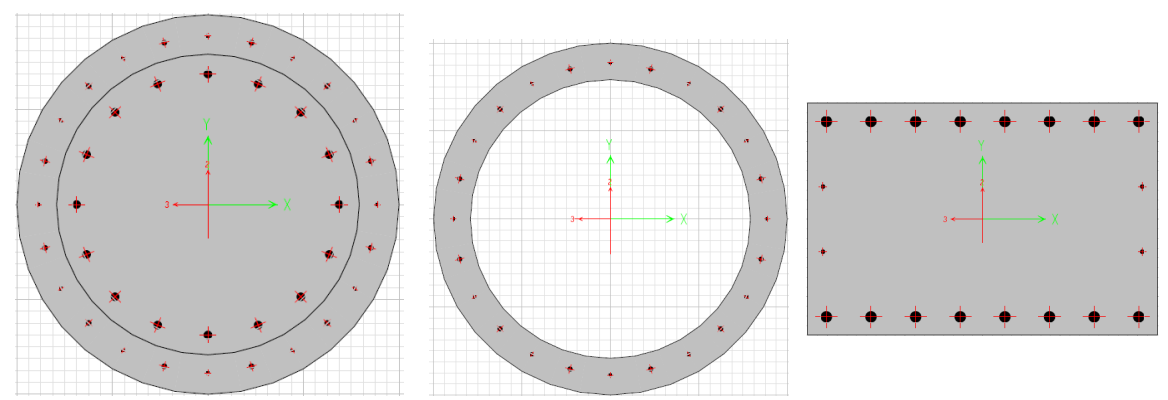

Figure 11. Bent Element Cross-Sections 
The cross-sections of the cap beam and the column were accurately modeled by using the subprogram offered in SAP2000 called Section Designer. Section Designer lets the user draw the shape of the cross-section and also include the steel reinforcement. Figure 11 shows the drawn sections used in the analysis.

\section{Piles}

The columns were considered fixed in the cap beam. Nonlinear springs along the pile shafts were used to model the resistance provided by the surrounding soil. The L-Pile software (2002) was used to compute the P-Y curves, based on the stiff sand soil model with free water at 15 depths.

To build an exact computer model of a structure beard against underground elements-piles it is necessary to know how interaction between soil and a pile can be simulated, to get more precise result of the analysis. The p-y curves is a strait interpretation of the relation between deflection of an element and soil pressure on a particular depth. The pressure from the soil on the element is distributed within certain length which depends on the number of springs assigned to it Figure 12.

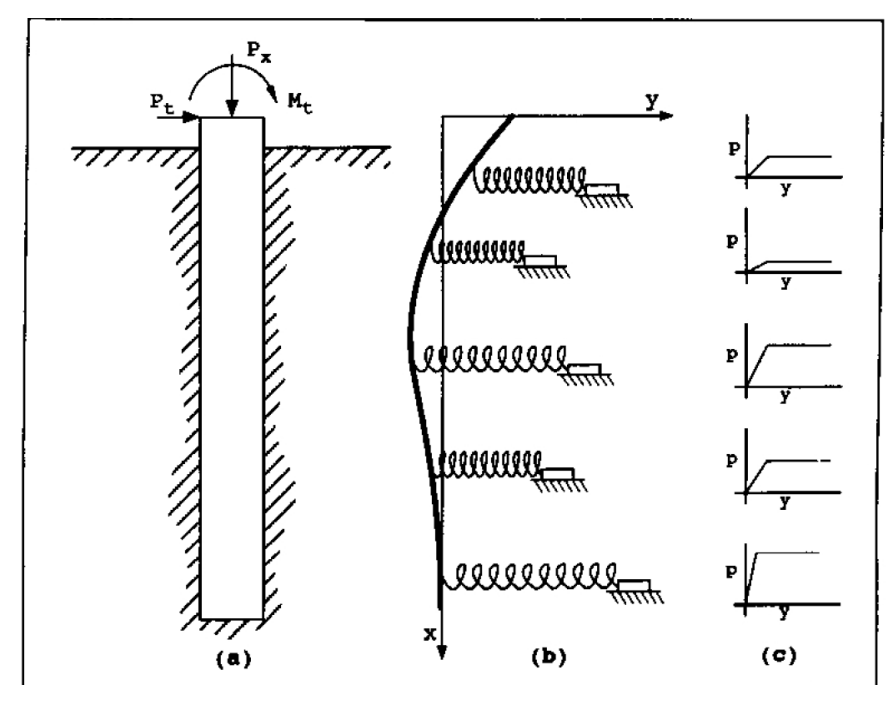

Figure 12. Model of laterally loaded pile

A physical definition of the soil resistance $p$ is given in Figure 13. There was made an assumption that the pile has been installed without bending so the initial soil stresses at the depth $x_{i}$ are uniformly distributed as shown in Figure 13b. If the pile is loaded laterally so that a pile deflection $y_{i}$ occurs at the depth $x_{i}$ the soil stresses will become unbalanced as shown in Figure 13c. Integration of the soil stresses yielding the soil resistance $p_{i}$ with units F/L equation 1. 


$$
\mathrm{p}_{\mathrm{i}}=\mathrm{E}_{\mathrm{s}} \mathrm{y}_{\mathrm{i}}
$$

where,

$\mathrm{E}_{\mathrm{s}}$ - a parameter with the units $\mathrm{F} / \mathrm{L}^{2}$, relating pile deflection $y$ and soil reaction $p$.

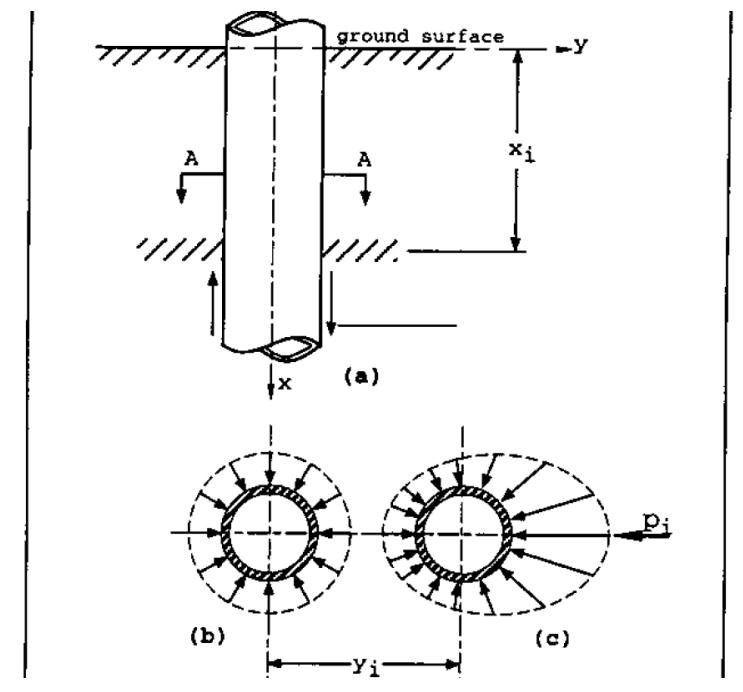

Figure 13. Definition of $p$ and $y$ as Related to Response of a Pile to Lateral Loading

Once the p-y curves at various depths of the pile have been obtained, a force-displacement relationship can be calculated by multiplying $\mathrm{p}$ with the tributary length of the pile between springs. Figure 14 shows a bilinearization of the force-displacement relationship at different depth based on the data retrieved from LPILE single pile analysis. These results were used to define multi-linear elastic links (springs) in SAP2000 in order to represent the SSI of the piles. The piles of all bents were assumed to extend $27 \mathrm{ft}$ under the ground, so all bents had the same pile modeling.

\section{Plastic hinge}

It is well known that well-confined concrete structures can deform inelastically without significant strength loss through several cycles of response. Ductility describes such ability of structures, which is often defined as the ratio of deformation at a given response level to the deformation at yield response. Commonly used ductility ratios include displacement ductility, curvature ductility and rotation ductility. In the software of XTRACT, developed by Imbsen \& Associates Company (2002) with the capability of analyzing structural cross sections, curvature ductility can be calculated for a given section and are defined in Equation 2 (Paulay and Priestley, 1992). 


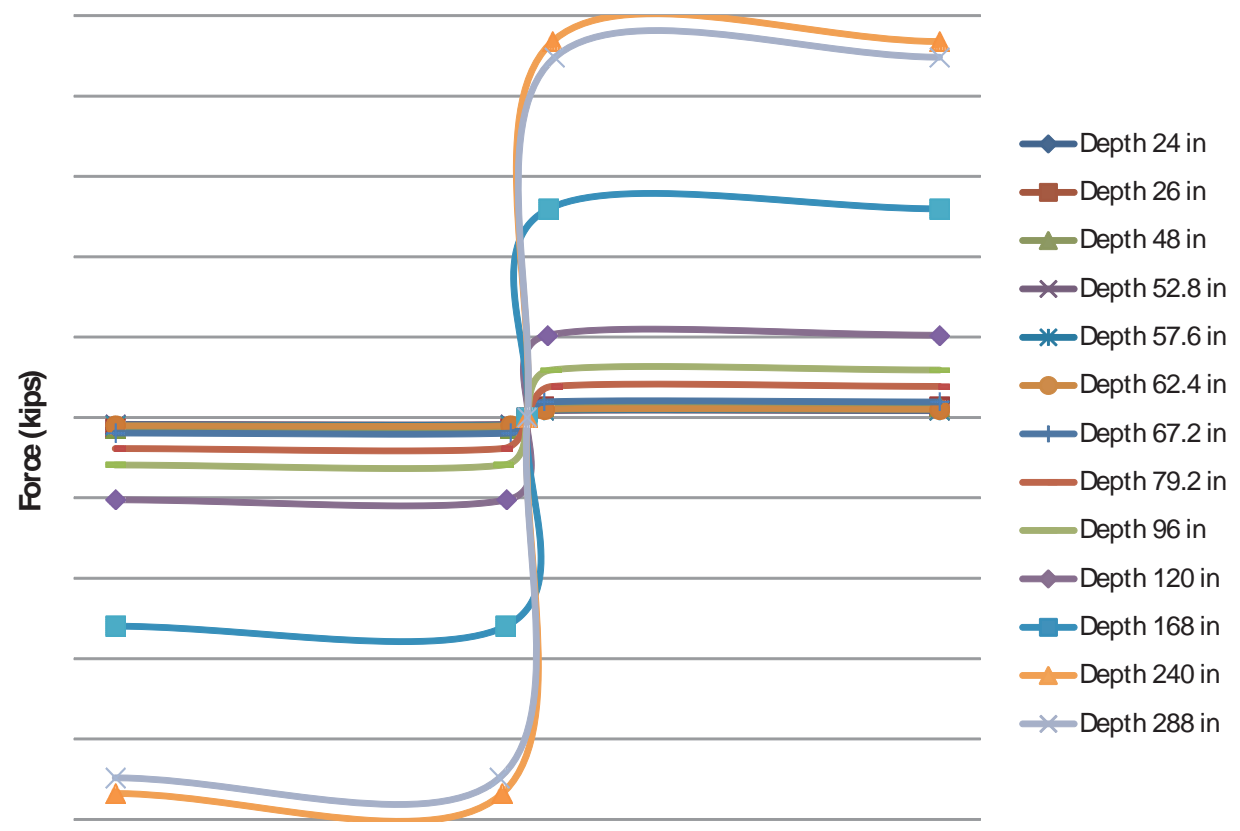

Displacement (in)

Figure 14. Bilinearized Force-Displacement of SSI at Different Depths

$$
\mu_{\varphi}=\frac{\varphi_{u}}{\varphi_{y}}=\frac{\varphi_{p}+\varphi_{y}}{\varphi_{y}}
$$

in which $\phi_{\mathrm{y}}$ is yield curvature, $\phi_{\mathrm{p}}$ is plastic curvature, and $\phi_{\mathrm{u}}$ is summation of yield curvature and plastic curvature that presents the ultimate curvature capacity of a section.

Figure 15 and Figure give a moment-curvature diagram for the column sections in the North Bound Bridge, calculated by the XTRACT. Curvature properties are section dependent and can be determined by numerical integration methods. Input data of a cross-section include nonlinear material properties of concrete and steel, and the detailed configuration of the section. For the North Bound bridge, all the columns have the identical section dimension, however, the moment-rotation relationships may not be the same because of the different axial loads.

\section{Hinge length}

The plastic hinge length for piles depends on whether the hinge is located at the pile/deck interface or is an in-ground hinge. For prestressed piles where the solid pile is embedded in the deck, the plastic hinge length at the pile/deck interface can be taken as (PIANC): 
Moments about the X-Axis - kip-in

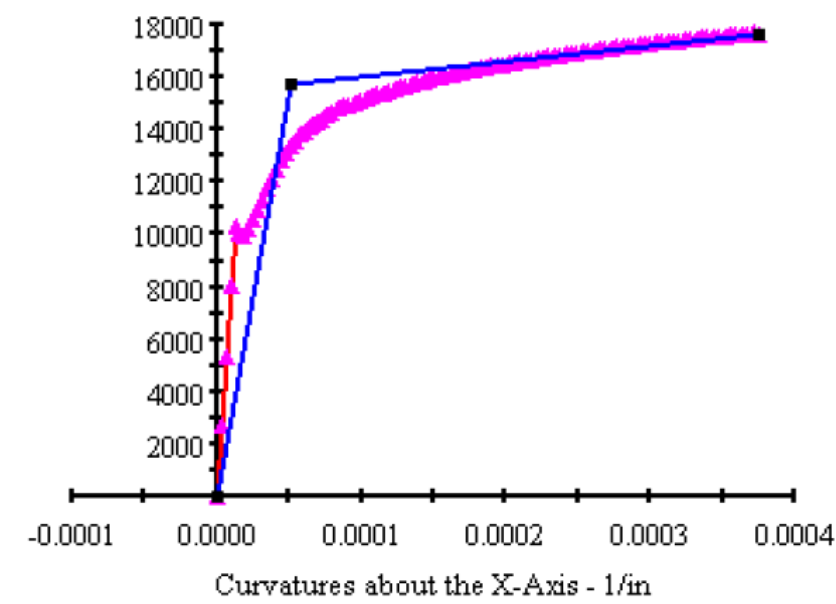

Moment Curvature Relation

$\longrightarrow$ Moment Curvature Bilinearization

Figure 15. Bilinearization of the Moment-Curvature Curve for Hollow Column

Moments about the X-Axis - kip-in

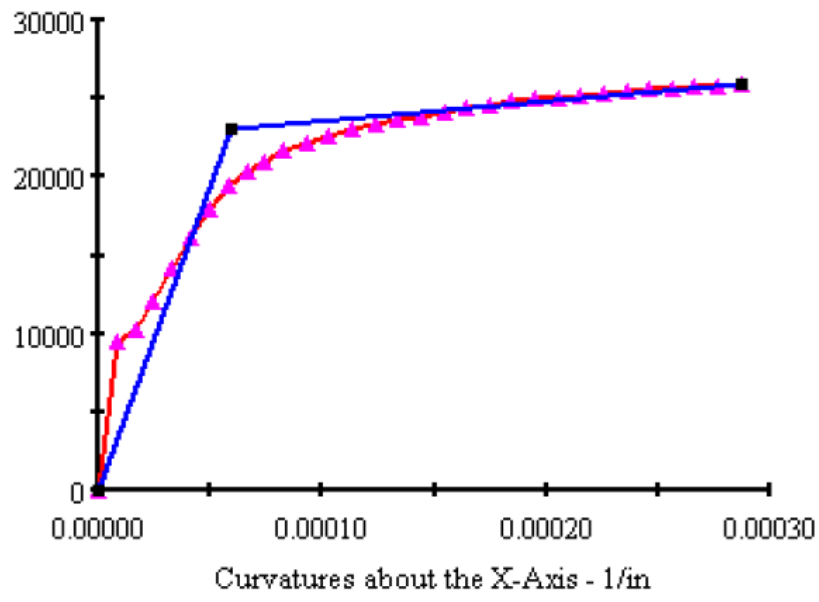

Moment Curvature Relation

$\longrightarrow$ Moment Curvature Bilinearization

Figure 16. Bilinearization of the Moment-Curvature Curve for Filled Hollow Column 


$$
\mathrm{L}_{\mathrm{p}}=0.5 \mathrm{D}_{\mathrm{p}}
$$

where,

$\mathrm{D}_{\mathrm{p}}$ - diameter of a pile

For in-ground hinges, the plastic hinge length depends on the relative stiffness of the pile and the foundation material. Because of the reduced moment gradient in the vicinity of the inground hinge, the plastic hinge length is significantly longer there. In this report CALTRANS interpretation of in-ground hinges for a non-cased pile shaft was used. Figure 17 describes the calculation steps provided by CALTRANS.

$$
\begin{aligned}
& \mathrm{L}_{\mathrm{p}}:=\mathrm{D}_{\mathrm{e}}+0.6 \cdot \mathrm{L} \\
& \mathrm{L}_{\mathrm{P}}=\text { Flastic hinge length (in) } \\
& L=\text { Length of pile shaft from } \\
& \text { ground surface to point of } \\
& \text { contraflexure above ground (ini) } \\
& \mathrm{D}_{\mathrm{e}}=\text { Diameter or least cross sectional } \\
& \text { dimension (ini) }
\end{aligned}
$$

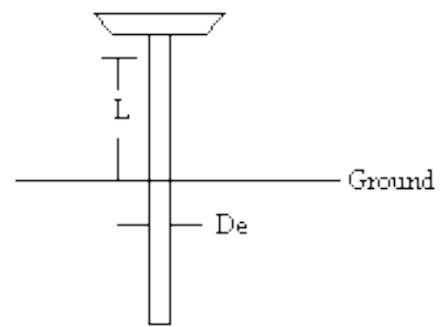

Figure 17. In-Ground Hinge Length

\section{Hinge location}

In order to locate the plastic hinge locations, a separate push over analysis was run on single column. Figure 18 shows the single column element modeled in SAP2000. Top of the column is restrained against rotation to represent the rigid connection between the column and the deck. The SSI is represented by links just as discussed for general bents. The pin connection at the bottom of the pile restricts the pile from vertical movement.

Figure 19 provides the moment diagram of the above column/pile under horizontal loading. The diagram has two points of maximum moment. The plastic hinge should be placed at these locations in order to represent the most conservative nonlinear behavior of the column/pile. 


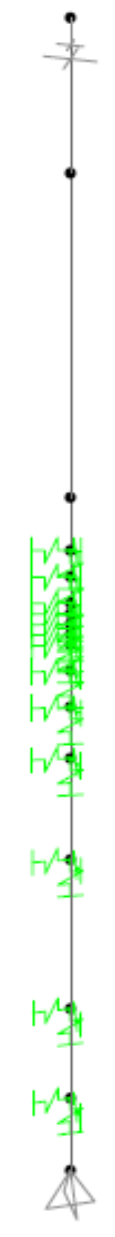

Figure 18. Single Column Finite Element Stick Model

The placement of the first hinge should be at the column/bent connection as expected before. The second hinge has to be place under the ground, but the location of maximum moment in that area changes in a pushover analysis. A parametric study was run in order to locate the worst location for an in-ground hinge. The placement of the in-ground hinge was varied for multiple pushover analysis. Figure 20 shows the results of this parametric study, where the hinge depth below ground level is compared to column top displacement capacity. The plot in Figure 20 shows that placing the hinge $20 \%$ of pile length under the ground would give a displacement capacity of 2.25 in, which is less than any other location. Figure 21 shows the placement of the plastic hinges in four column bent. 


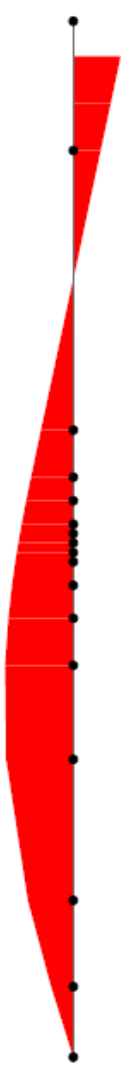

Figure 19. Moment Diagram of Single Column under Horizontal Load

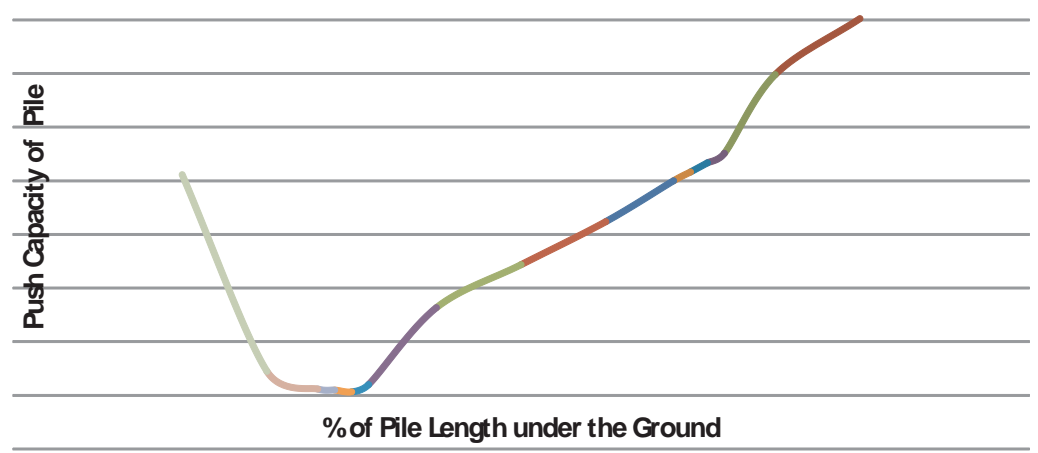

Figure 20. Single Column Parametric Study Results 


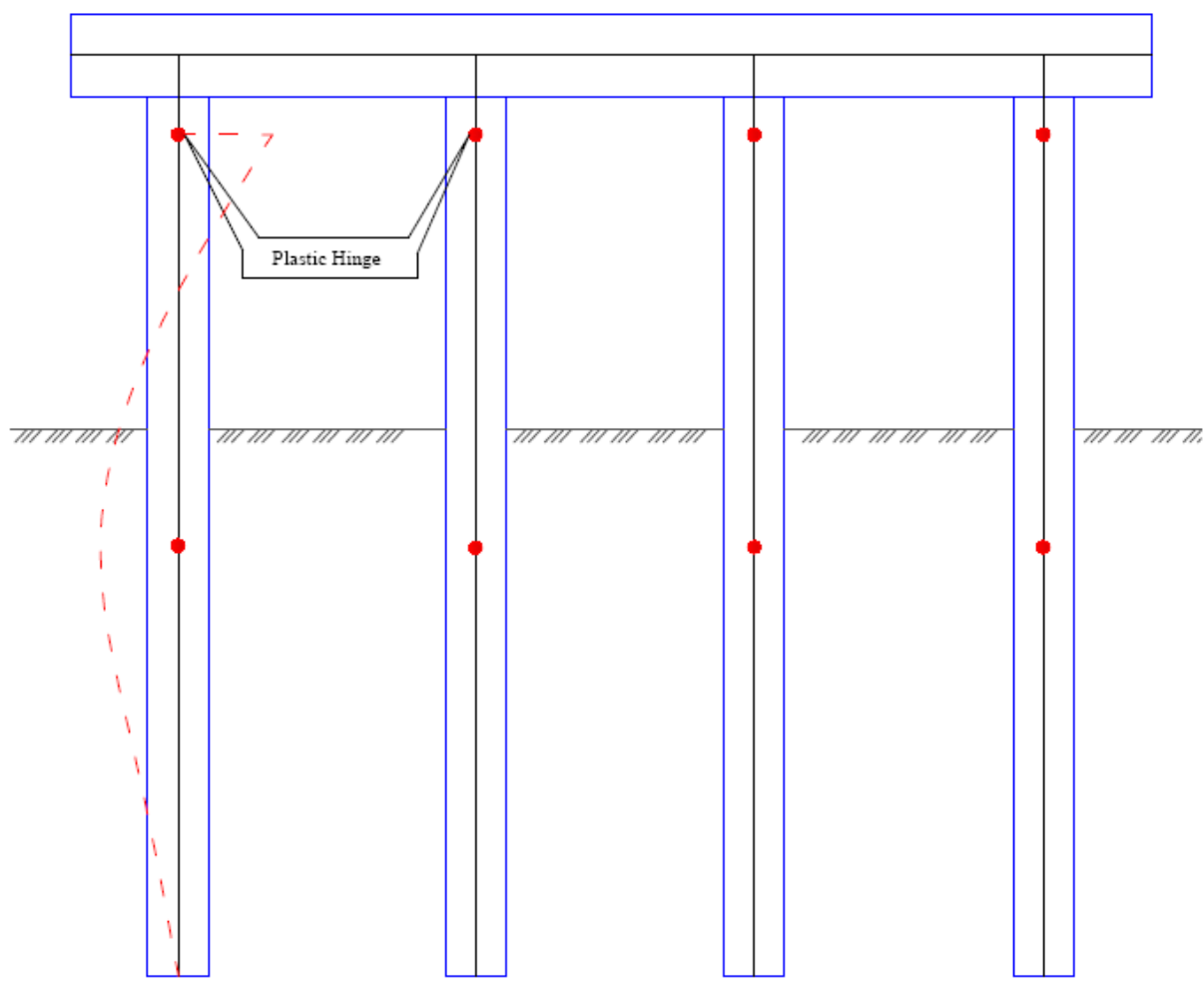

Figure 21. Location of the Plastic Hinge

\section{Plastic hinge property}

The Manual of SAP2000 recommends a distributed plastic hinge model assuming 0.1 of element length as the plastic hinge length, but information on how to define distributed plastic hinge properties is not provided. In this research, a concentrated plastic hinge model is used with the assumption that plastic rotation will occur and concentrate at mid-height of a plastic hinge. Input hinge properties consist of the section yield surface, plastic rotation capacity, and acceptance criteria.

A plastic rotation, $\theta_{p}$, can be calculated by the plastic curvature given the equivalent plastic hinge length $L_{p}$ as shown in Equation 4.

$$
\theta_{p}=\varphi_{p} L_{p}=L_{p}\left(\varphi_{u}-\varphi_{y}\right)
$$

The plastic rotation is an important indicator of the capacity of a section to sustain inelastic deformation and is used in SAP to define column plastic hinge properties. FEMA 356 provides 
a generalized force-deformation relation model shown in Figure 22 for the nonlinear static analysis procedure, which is the defaulted model in SAP for the Axial-Moment hinge.

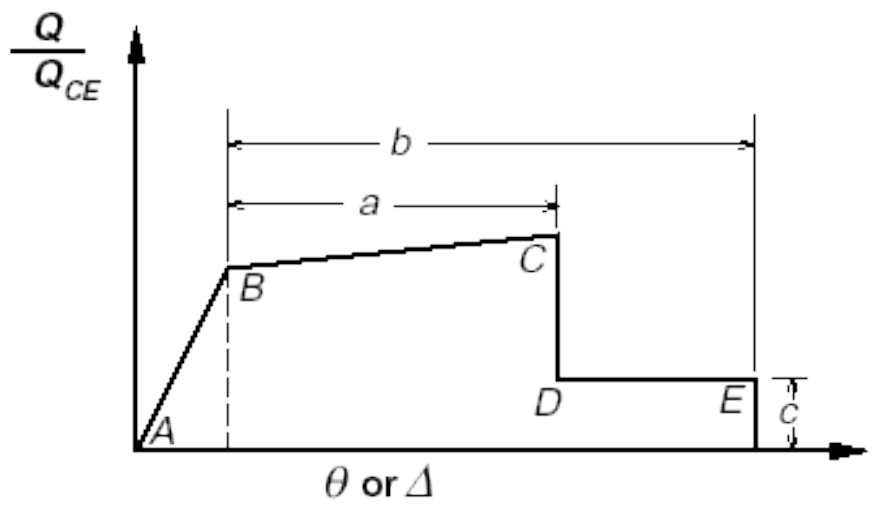

Figure 22. Generalized Force-Deformation Relations for Concrete Elements (FEMA-356)

Three parameters, $a, b$ and $c$ are defined numerically in FEMA-365, and are permitted to be determined directly by analytical procedures. The moment and rotation are normalized by yield moment and yield rotation respectively, i.e., $\frac{M}{M_{y}}$ and $\frac{\theta}{\theta_{y}}$. By default SAP will calculate the yield forces and the yield rotation based on reinforcement and section provided.

In Table 6-8 of FEMA 356, modeling parameters and numerical acceptance criteria are given for reinforced concrete columns in various categories. Columns investigated are all primary structural elements. A conforming transverse reinforcement is defined by hoops spaced in the flexural plastic hinge region less than or equal to $\frac{d}{3}$, and the strength provided by the hoops $(V s)$ being greater than three-fourths of the design shear. Thus, the category of the column is decided in Table 6-8 of FEMA 356, and values and relationship of the performance levels can be utilized.

In SAP, an absolute rotation value can overwrite the default value in defining a hinge property. The plastic rotation capacity angle, $a$, calculated with Equation 4-12 for a given column is at point $C$. The ultimate rotation angle, which is inputted as $b$ in SAP, is taken as 1.5 times the plastic angle. It is indicated at point $\mathrm{E}$, which defines a local failure at a plastic hinge. A larger value could be used to allow the structure to form a global failure due to instability.

The three discrete structural performance levels are Immediate Occupancy (IO), Life Safety (LS) and Collapse Prevention (CP) shown in Figure 23.

The ultimate plastic hinge angle calculated by the XTRACT was taken as the Collapse Prevention level. Its value was indicated as " $a$ " in Figure 1. The permissible deformation for the Life Safety performance level is taken as three quarters of the plastic rotation capacity " $a$ ". 


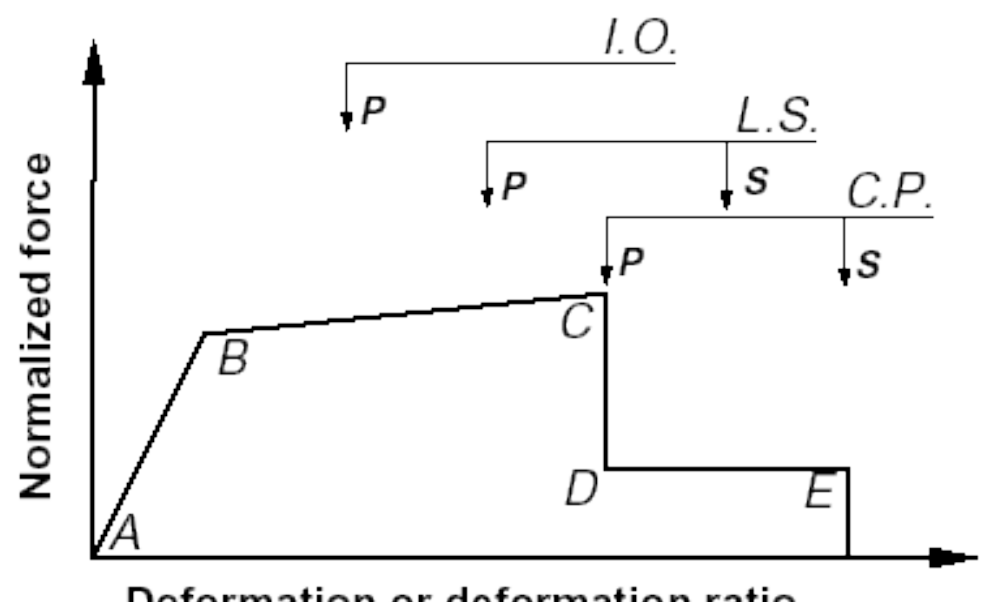

Figure 23. Performance Level on Generalized Force-Deformation Relations for Concrete Elements (FEMA-356)

The increase of moment strength at point $C$ is taken as the over strength factor computed by XTRACT, ignoring the strength softening effect. The actual moment strength at point $C$ is the product of the factor and the yielding moment. FEMA 356 defines a 0.2 residual strength ratio before plastic hinge eventually fails. Figure 24 presents moment-rotation curves for one of the columns.

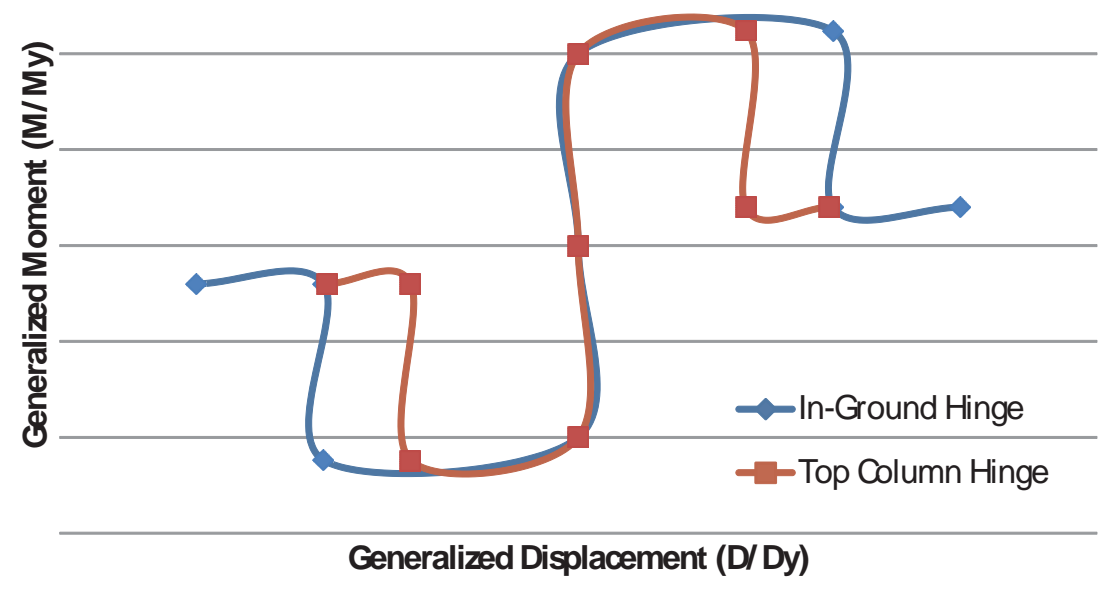

Figure 24. Moment-Rotation Relationship of the Columns 
A concrete interaction surface was obtained from XTRACT for the frame hinges under combined bending and axial load. A generated interaction surface is shown in Figure 25.

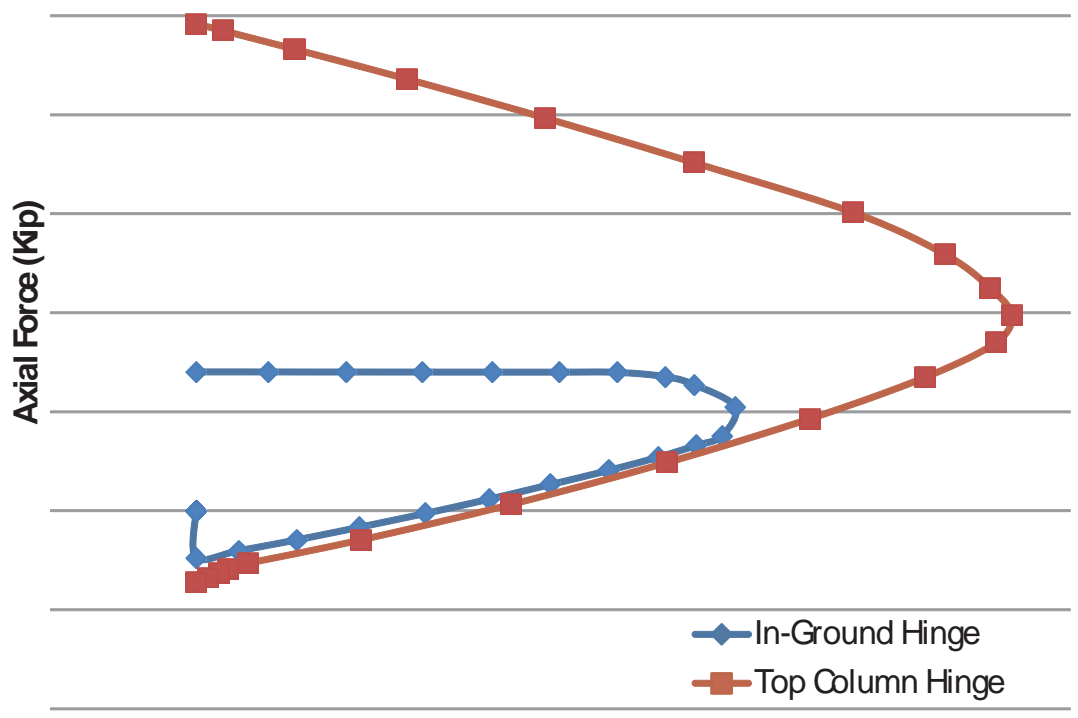

Moment (kin)

Figure 25. Axial Load-Moment Interaction Curve (Compression force is negative)

\section{Results}

The results of the pushover analysis are organized in the following pages. Each bent has two pages of results. The first page shows the general characteristics of the bent and the push over curve. The second page shows the results of the step by step push over analysis and the development of hinges. The first and the last bent on the plan are abutments, so they are not included in this report.

Maximum displacement capacity exhibited is 3.9 inches by the fifth bent. The lowest bent capacity is 2.08 inches by the second bent. The reason for this low displacement capacity in bent number two is because of its shorter columns compared to other bents.

Using two hinges per column creates a much lower capacity than using only one hinge at the top of the column. The shear force capacity stays almost the same, but the ductility reduces for all bents. 


\section{Author details}

Vitaly Yurtaev ${ }^{1,2^{*}}$ and Reza Shafiei ${ }^{1,2}$

*Address all correspondence to: vitalijj@gmail.com

*Address all correspondence to: vitalijj@hotmail.com

1 Moscow State University of Railways, Department Of Civil Engineering, (MIIT), Moscow, Russia

2 Washington State University, Pullman, WA, USA

\section{References}

[1] FEMA 356(2000). table , 6-8.

[2] Priestley, M. J. N. Frieder Seible, Gian Michele. Seismic Design and Retrofit of Bridges, Wiley-IEEE, (1996). p., 1996, 200-250.

[3] Pui-shum, B. Shing, National Science Foundation (U. S.), Tadaaki Tanabe, Nihon Gakujutsu Shinkōkai, National Science Foundation (U.S.), Nihon Konkurīto Kōgaku Kyōkai, Nihon Gakujutsu Shinkōkai, Nihon Konkurīto Kōgaku Kyōkai, Modeling of inelastic behavior of RC structures under seismic loads, ASCE Publications, (2001). p., 2001, 425-450.

[4] Rainer, J. H, \& Vanselst, A. Dynamic properties of Lions Gate Bridge', Proc. Conf. on Dynamic Response of Structures: Instrumentation,.esting Methods and System Identi,cation, ASCE Specialty Conf., University of California, (1976). , 243-252.

[5] Rainer, J. H, \& Pernica, G. Dynamic.esting of a Modern Concrete Bridge, National Research Council of Canada, (1979). , 447.

[6] Nishimura, A, \& Haya, H. Assessment of the structural integrity of bridge foundation by the impact vibration test', GEO-COAST, Yokohama, (1991). , 719-724.

[7] Shepherd, R, \& Sidewell, G. K. Investigations of the dynamic properties of concrete bridges, 4th Australian Conf. on the Mechanics of Structures and Materials, University of Queensland, Brisbane, Australia, (1977). , 261.

[8] Dougla, B. M, Drown, C. D, \& Gordon, M. L. Experimental dynamics of highway bridges', in G. Hart (ed.) Proc. Specialty Conf. on Dynamic Response of Structures, Experimentation, Observation, Prediction and Control, ASCE, New York, (1981). , 698. 